Gut, 1981, 22, 817-822

\title{
Abnormalities of neutrophil function do not cause the migration defect in Crohn's disease
}

\author{
C Ó MORȦIN,* A A SEGAL, † D W A LKER, AND A J LEVI \\ From the Clinical Research Centre and Northwick Park Hospital, Harrow, Middlesex
}

SUMMARY Skin window tests were performed on 60 patients with Crohn's disease, 20 with ulcerative colitis, 16 with peptic ulceration, and 40 healthy controls. The numbers of neutrophils that migrated into the skin window chambers were significantly lower in patients with Crohn's disease. This abnormality was unrelated to the activity of the disease, site of involvement, or treatment. No significant abnormalities were found in the patients with other diseases of the gastrointestinal tract. The abnormality of neutrophil migration in the Crohn's patients does not seem to be due to a cellular defect, as neutrophils from patients with Crohn's disease migrate and phagocytose normally in vitro. Sera from patients with Crohn's disease did not inhibit cell migration or contain inhibitors of chemotaxis. The addition of serum that had been activated with zymosan to the chamber enhanced the emigration of neutrophils from the skin of patients with Crohn's disease. These results suggest that the depression of neutrophil migration into skin windows that is normally observed in Crohn's disease is due to a deficient local inflammatory response. This defective inflammatory response in Crohn's disease and the consequent delay in the accumulation of neutrophils could explain granuloma formation, the high recurrence rate after surgery, and the clinical course of exacerbations and remissions.

A striking abnormality of neutrophil function has been described in Crohn's disease. The numbers of neutrophils migrating into skin window chambers were found to be abnormally low. ${ }^{1}$ It was proposed that this abnormality could be important in the pathogenesis of the disease. A similar abnormality has been described in another granulomatous condition, sarcoidosis. ${ }^{2}$

Chronic granulomatous disease is a condition in which neutrophil dysfunction has been clearly established as playing a causal role. The lesions in the bowel in this condition are histologically indistinguishable from Crohn's disease. ${ }^{3}$ These studies were conducted to determine the nature of the defect of neutrophil migration in Crohn's disease.

\section{Methods}

Skin window tests were performed on 40 healthy controls and 60 patients with Crohn's disease. Two

*Address for correspondence: C Ó Moråin, Clinical Research Centre and Northwick Park Hospital, Watford Road, Harrow, Middlesex HAI 3 UJ.

†Present address: Department of Clinical Haematology, University College Hospital Medical School, University Street, London WC1.

Received for publication 1 April 1981 areas of $0.8 \mathrm{~cm}^{2}$ were abraded on the forearm with a battery-powered dental drill. The uniformity of the area of abrasion was ensured by the use of a plastic template. A skin window chamber was glued in place over the abraded area. ${ }^{1}$ Autologous serum $(0.7 \mathrm{ml})$ was injected into the chamber. It was aspirated after five hours and the number of neutrophils migrating into the chamber was counted. The diagnosis of Crohn's disease was made on histological, clinical, and radiological grounds. Other clinical features of the patients are shown in the Table. A patient was considered to have active disease if hospitalisation was required. Skin window tests were carried out on other groups of patients with a variety of different illnesses including ulcerative colitis $(n=20)$ and peptic ulcer $(n=15)$. In a separate series of studies skin window tests were conducted on 18 patients with Crohn's disease and 18 healthy controls. Four abrasions were made and covered by chambers. Autologous serum was placed in two of the chambers. Zymosan activated serum was prepared by incubating $\mathrm{AB}$ serum (Au antigen negative) with zymosan $1 \mathrm{mg} / \mathrm{ml}$ at $37^{\circ} \mathrm{C}$ for 60 minutes and then at $56^{\circ} \mathrm{C}$ for 30 minutes. The zymosan 
Table Relationship of sex, age, localisation, activity, and treatment of patients with Crohn's disease who had skin window tests

\begin{tabular}{lr}
\hline Males & 29 \\
Females & 29 \\
Age (yr) & \\
$<20$ & 6 \\
$20-40$ & 34 \\
$>40$ & 20 \\
Site & \\
Small bowel & 14 \\
Ileocaecal & 16 \\
Small and large bowel & 4 \\
Large bowel & 17 \\
Activity & \\
None after resection & 9 \\
Active & 26 \\
Inactive & 34 \\
Treatment & \\
None & 29 \\
Prednisone & 16 \\
Salazopyrine & 7 \\
Levamisole & 5 \\
Azothiaprine & 3 \\
\hline
\end{tabular}

was removed by centrifugation and stored at $-20^{\circ} \mathrm{C}$. This activated serum was placed in the other two chambers. Heterologous AB serum (Au antigen negative) was used as the chemotactic agent in another 10 patients with Crohn's disease.

NEUTROPH IL M I GRATION IN VITRO Neutrophils and sera were collected from patients with Crohn's disease who had neutrophil counts in the skin window chamber $<0.37 \times 10^{6} \mathrm{cells} / \mathrm{cm}^{2}$ and control subjects who had $>1.77 \times 10^{6}$ cells/ $\mathrm{cm}^{2}$. Human blood was obtained from both healthy controls and patients with Crohn's disease. To prepare the neutrophil suspension the blood was mixed with heparin 10 units $/ \mathrm{ml}$. Red blood cells were sedimented for 45 minutes at room temperature with an approximately equal volume of dextran 70 (Lomodex R70, Fisons Ltd). The resulting supernatant was layered on top of FicolPaque (Pharmacia) and centrifuged in an MSE centrifuge at $4500 \mathrm{rpm}$ for 20 minutes. The plasma, lymphocytes, and Ficol-Paque were drawn off. The remaining red blood cells were lysed by an osmotic shock. The pure preparation of neutrophils was resuspended in Hanks's balanced salt medium to a concentration of $2 \times 10^{6} / \mathrm{ml}$ for assays of chemotaxis and to a concentration of $2 \times 10^{7} / \mathrm{ml}$ for measurements of oxygen consumption. Neutrophil migration was measured by a modification of the Boyden chamber technique. ${ }^{4}$ The leucocyte suspension $0.25 \mathrm{ml}$ was added to the upper chamber and inverted onto a $3 \mathrm{~m} \mu$ pore size Millipore filter which had been placed on an antibiotic disc saturated. with $0.2 \mathrm{ml}$ of a chemotactic agent. After incubation for one to two hours (depending on the chemotactic agent used) at $37^{\circ} \mathrm{C}$, in a humidified chamber, the filters were removed and stained with Harris haematoxylin. Migration was measured by the leading front method $^{5}$ taking the average of five readings per filter. All assays were performed in duplicate.

C H E M O T A C T I C A G E N T S

Casein (BDH Ltd) was dissolved in alkali and a concentration of $1 \mathrm{mg} / \mathrm{ml}$ and then neutralised to a $\mathrm{pH}$ of $\mathbf{7 \cdot 4}$. The solution was centrifuged in an MSE bench centrifuge at $4500 \mathrm{rpm}$ at room temperature for 20 minutes; any precipitate was discarded. It was stored as a standard solution at $-20^{\circ} \mathrm{C}$. Zymosan-activated serum was prepared as outlined above. E. coli derived chemotactic factor was prepared from an overnight growth of E.coli in Medium 199 (Flow Lab) by centrifuging it at $2000 \mathrm{~g}$ for 30 minutes at $0^{\circ} \mathrm{C}$ and filtering the supernatant through a Millipore filter $(0 \cdot 2 \mu)$. Checkerboard assays were carried out using the method of Zigmond and Hirsch in which different concentrations of the chemoattractant were placed above and below the filter. ${ }^{5} E$. coli supernatant ${ }^{6}$ and $\mathrm{ZAS}^{7}$ were preincubated for 30 minutes at $37^{\circ} \mathrm{C}$ with $5 \%$ serum from patients with Crohn's disease and $5 \%$ serum from healthy controls before testing their ability to attract neutrophils through the filter. To test for inhibition of the movement of control cells by patient's serum ${ }^{8}$ neutrophils were preincubated at $37^{\circ} \mathrm{C}$ for 30 minutes in the presence of $10 \%$ Crohn's disease serum before assaying chemotaxis.

\section{O X Y G E N CON S U M P T I O N}

Oxygen consumption was measured in a closed thermostatically controlled (at $37^{\circ} \mathrm{C}$ ) plastic chamber attached to a Clarke type oxygen electrode. Neutrophils from 10 patients with Crohn's disease in a concentration of $2 \times 10^{7}$ cells $/ \mathrm{ml}$ were exposed to Latex particles (Difco $0.81 \mu$ diameter), opsonised with human IgG (Lister Institute) ${ }^{9}$ and to $E$. coli opsonised with pooled $\mathrm{AB}$ serum.

B I O A S S A Y OF S K IN W IN D O W F L U ID Skin window fluid aspirated after (five hours) of being in contact with the abraded area was assayed for bradykinin, histamine, and prostaglandin E2.10

The permission of the Ethical Committee was obtained for all the experiments. 


\section{Results}

The number of cells migrating into skin window chambers was significantly lower in patients with. Crohn's disease (range 0.01 to 2.01 , median 0.37 , $\mathrm{n}=60$ ) than in normal controls (range 0.38 to $5 \cdot 8$, median $1 \cdot 77, \mathrm{n}=40, \mathrm{P}<0 \cdot 001$, Wilcoxon rank test, Fig. 1). There was no relationship to disease

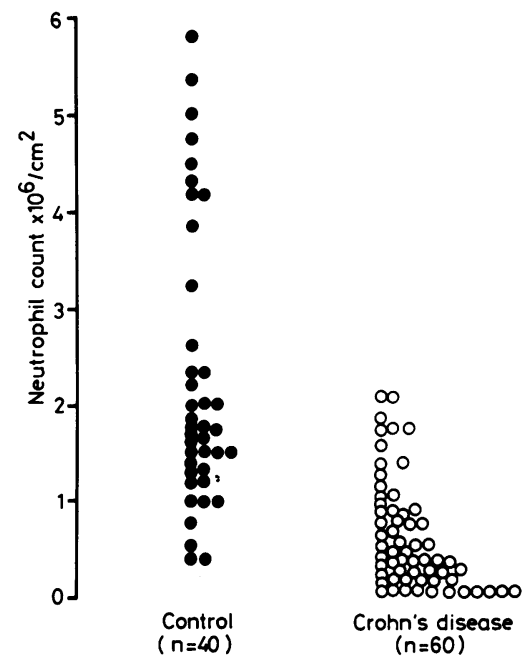

Fig. 1 Migration into skin windows of neutrophils from patients with Crohn's disease and controls.

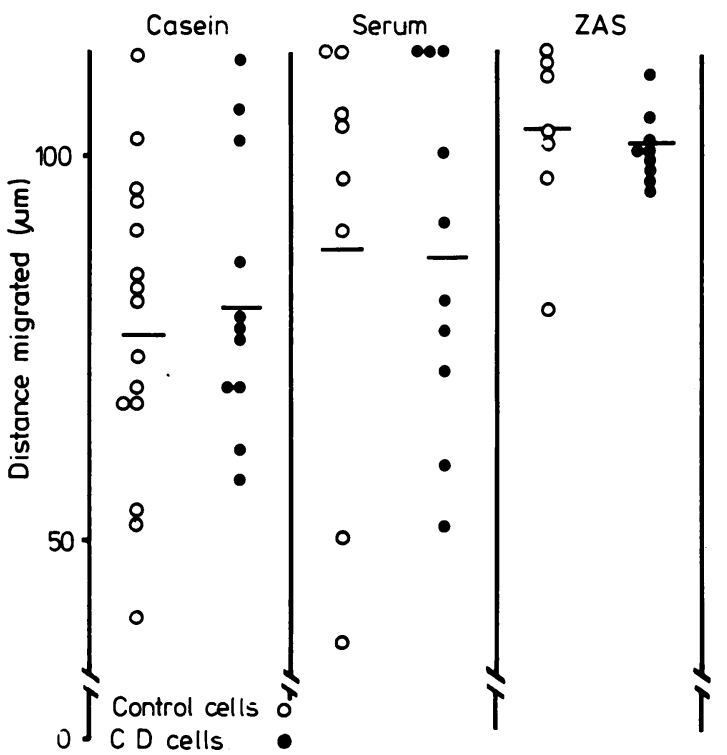

Fig. 2 Migration of neutrophils in vitro isolated from patients with Crohn's disease and healthy controls through millipore membranes towards casein, serum, and zymosan-activated serum (ZAS). activity, site of involvement, or treatment $(P<0 \cdot 4$, Wilcoxon rank test). There was no significant difference in the number of cells migrating between normal subjects and other disease groups studied; these included ulcerative colitis (range 0.07 to $7 \cdot 0$, median $1 \cdot 31, \mathrm{n}=20$ ) and peptic ulcer (range $0 \cdot 21$ to $4 \cdot 8$, median $1 \cdot 8, n=16$ ).

The checkerboard assay suggested that ZAS and casein were chemotactic, that cells moved in a positive concentration, and that serum at a concentration greater than $10 \%$ was chemokinetic. Cells migrated even in the absence of a positive concentration gradient. We found no significant difference in distance migrated by cells isolated from controls and Crohn's disease (Fig. 2). To rule out the possibility of an intrinsic cellular defect in patients with Crohn's disease, all possible combinations of neutrophils and serum were used. No significant difference in migration was seen in any combination. There was no evidence of cell directed inhibition in that there was no significant difference in the migration of neutrophils isolated from healthy controls suspended and preincubated in $10 \%$ control serum or $10 \%$ serum obtained from patients with Crohn's disease; there was also no evidence for an inactivator of chomotactic factor in that there was no significant difference in the distance migrated when ZAS and E. coli supernatant was preincubated in $5 \%$ serum from controls and $5 \%$ serum from patients with Crohn's disease (Fig. 3).

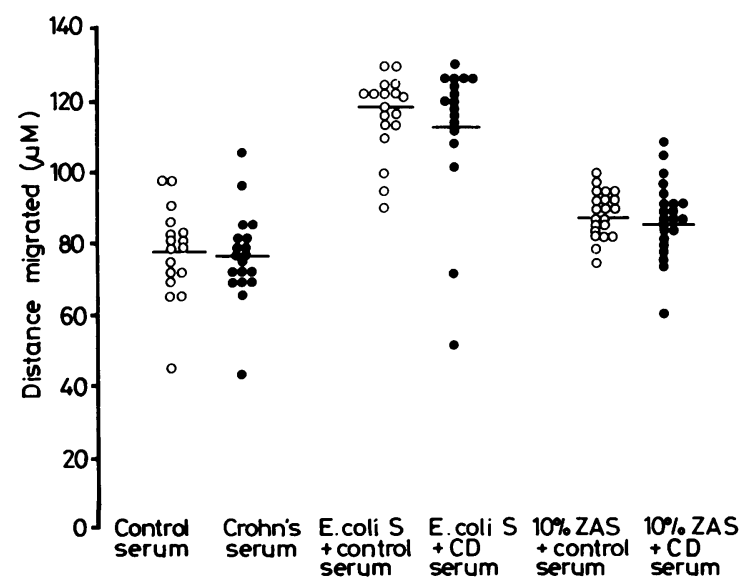

Fig. 3 Migration of neutrophils, isolated from healthy controls, suspended in $10 \%$ normal control sera and $10 \%$ sera from patients with Crohn's disease. Migration of neurophils towards E. coli supernatant and $10 \%$ zymosan-activated serum preincubated with $5 \%$ control sera and $5 \%$ sera from patients with Crohn's disease. 


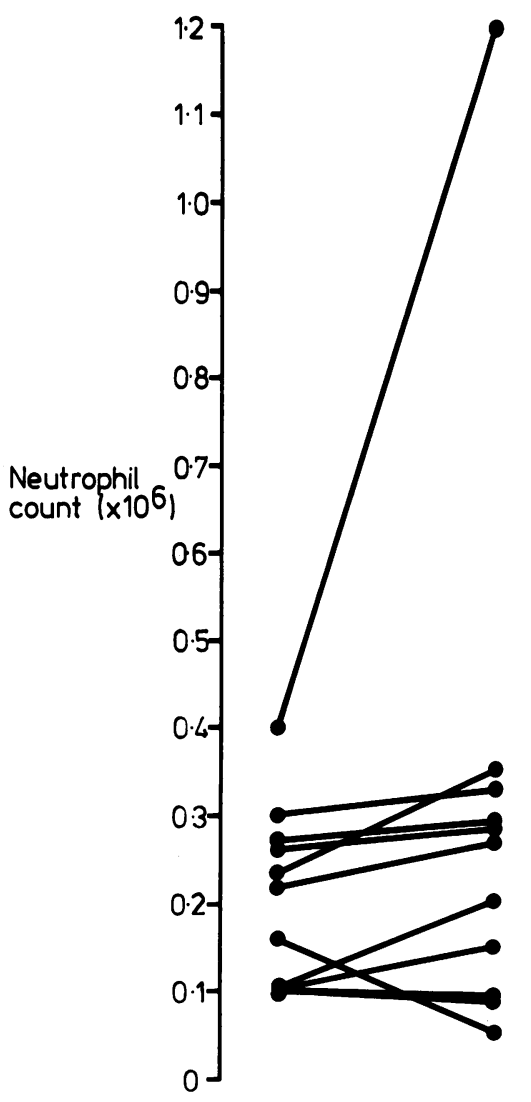

Fig. 4 Migration of neutrophils into skin windows in patients with Crohn's disease in the presence of their own serum and in the presence of $A B$ serum.

Additional studies with skin windows showed that group AB serum from healthy controls did not enhance migration significantly in patients with Crohn's disease, except in one patient (Fig. 4.) An increase did occur with zymosan-activated serum but was significantly lower $(\mathrm{P}<0.001)$ (Wilcoxon rank test) when compared with healthy controls (Fig. 5). A plot of the square root transformation of the mean showed that enhanced response to ZAS in Crohn's disease was identical with that in healthy controls (Fig. 6).

There was no significant difference in histamine content of skin window fluid from controls (19.4 \pm $10 \mathrm{ng} / \mathrm{ml}$, mean $\pm \mathrm{SD}, \mathrm{n}=11$ ) and Crohn's disease $(15 \cdot 9 \pm 6 \cdot 8$, mean $\pm S D, n=11)$. Prostaglandin $E_{2}$ and bradykinin-like substances levels were below the levels detectable in a bioassay.

Neutrophils isolated from Crohn's disease showed the same rate of $\mathrm{O}_{2}$ consumption $(35.7 \pm$ $4 \cdot 5 . \mathrm{nmol} / \mathrm{min}$, mean $\pm \mathrm{SE}$ ) as neutrophils from

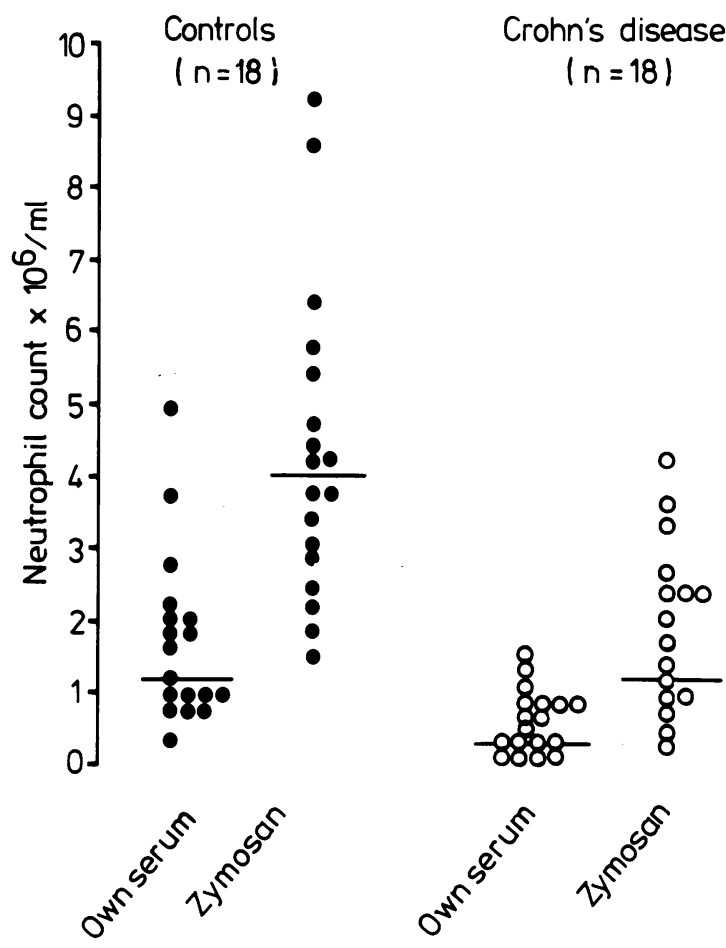

Fig. 5 Migration of neutrophils into skin windows in the presence of their own serum and zymosanactivated serum in healthy controls and patients with Crohn's disease.

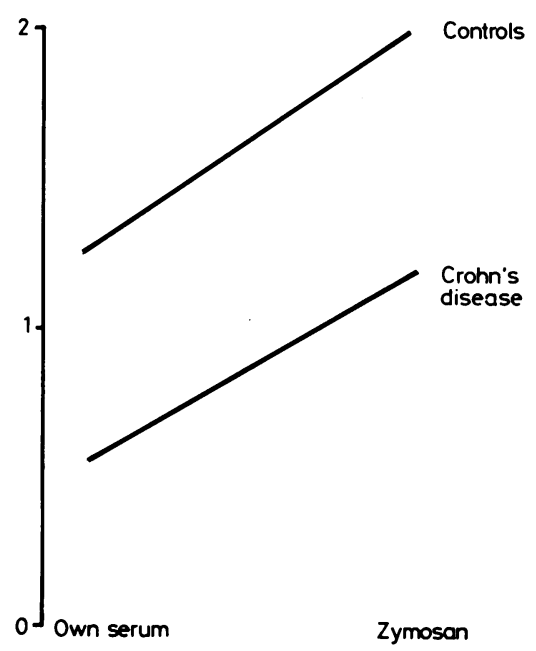

Fig. 6 Square root transformation of the mean of the results shown in Fig. 5. The two lines are parallel indicating similar enhancement. 
healthy controls $(37 \cdot 1 \pm 5 \cdot 1 \mathrm{nmol} / \mathrm{min}$, mean $\pm \mathrm{SE})$. There was no significant difference in rate of oxygen consumption when neutrophils from patients with Crohn's disease $(46 \cdot 35 \pm 4 \cdot 4 \mathrm{nmol} /$ min, mean \pm SE) were exposed to opsonised bacteria compared with healthy controls $(45 \cdot 2 \pm$ $7 \cdot 2 \mathrm{nmol} / \mathrm{min}$, mean $\pm \mathrm{SE}$ ).

\section{Discussion}

We have confirmed that patients with Crohn's disease have a depressed neutrophil migration into skin window chambers. ${ }^{1}$ This abnormality appears to be unrelated to the site or severity of the disease or to the drug or surgical therapy of the patient. It does not appear to be due to a primary cellular defect, as in vitro tests of neutrophil function were normal. Neutrophils from these patients showed a normal oxygen consumption response when exposed to opsonised Latex particles and bacteria. Therefore the abnormality is clearly different from that observed in chronic granulomatous disease. Furthermore, we found no abnormalities of chemotaxis when Crohn's cells were studied in vitro. A variety of chemotactic agents were used, as they may have different receptor sites on the neutrophils; we also used serum, a chemokinetic agent, as it is suggested that chemotaxis and chemokinesis could be controlled by distinct cellular mechanisms. ${ }^{12} \mathrm{~A}$ recent report suggested the presence in these patients of an inhibitory factor which diminishes chemotaxis, which correlated with the disease activity was probably due to acute phase proteins. ${ }^{13}$ In contradistinction, in our studies, serum from patients with Crohn's disease did not inhibit migration after preincubation with neutrophils. Supportive evidence that poor attractant properties of the patient's serum are not responsible for reduced migration into the chambers comes from our skin window studies. Serum from healthy controls did not normalise neutrophil migration into the skin window chamber.

Increased amounts of chemotactic factor inactivation have been found in patients with cirrhosis of the liver, ${ }^{13}$ sarcoidosis ${ }^{6}$ and Hodgkin's disease. ${ }^{14}$ When we used the same laboratory procedures outlined in these reports, sera from patients with Crohn's disease did not inhibit migration when preincubated with chemotactic agents. It is therefore unlikely that there is an increase in the inactivators of circulating chemotactic factor in Crohn's disease.

The defect is not obviously due to the lack of a chemotactic factor released at the site of in- flammation in vivo. Several substances that attract neutrophils are generated at the inflammatory site including complement components, histamine, and prostaglandins. Although we were unable to measure the levels of most of these compounds, we failed to show any difference in histamine levels at the site of abrasion in Crohn's disease. Zymosan-activated serum, which activjates complement by the alternate pathway, did not return the response to normal in patients with Crohn's disease, although it did cause some enhancement. The increase in the number of cells migrating in the presence of zymosan-activated serum was similar for both the Crohn's patients and the healthy controls when the square root transformation of the mean was plotted. This abnormality could be a primary event and predispose the patient to the acquisition of the disease. Neutrophils are the predominant cell in the acute inflammatory reaction and the first to arrive. A depression of this migration would reduce the ability of the patient to deal with material, including antigenic or infective material, that might cross the mucosal barrier. This could explain granuloma formation, a characteristic histological finding in Crohn's disease. A granuloma probably only occurs when the phagocytes are unable to degrade foreign materials in the tissues and persists as long as the undegraded material remains in the tissues. ${ }^{1.5}$ In Crohn's disease this may occur because the material is inherently indigestible or because of a failure of the individual's phagocytes to process material that would be harmless to the cells of normal subjects. In addition to granuloma formation, this defective inflammatory response could explain the high recurrence rates after surgery and the clinical course of exacerbations and remissions.

The authors are grateful to Dr Kobza Black, Institute of Dermatology, London, for the bioassay result. CÓM is an Eaton Research Fellow.

\section{References}

${ }^{1}$ Segal AW, Loewi G. Neutrophil dysfunction in Crohn's disease. Lancet 1976; 2:219-21.

${ }^{2}$ Gange RW, Black MM, Carrington P, McKeron R. Defeotive neutrophil migration in sarcoidosis. Lancet 2:379-81.

${ }^{3}$ Ament ME, Ochs HD. Gastrointestinal manifestations of chronic granulomatous disease. $N$ Engl J Med 1973; 288:382-7.

${ }^{4}$ Aggett HPJ, Harries JT, Harvey BAN, Soothill JF. An inherited defect of neutrophil mobility in Shwachmann's syndrome. J Paediatr 1979; 94:391-4. 
${ }^{5}$ Zigmond SH, Hirsch JC. Leucocyte locomotion and chemotaxis. New methods for evaluation and demonstration of cell-derived chemotactic factor. J Exp Med 1973; 137:387-410.

${ }^{6}$ Maderazo EC, Ward PA, Woronick CL, Kubik MA, De Graff AL. Leucotactic dysfunction in sarcoidosis. Ann Intern Med 1976; 8:414-9.

'Blumenfeld W, Territo M. A chemotactic inhibitor produced by blast cells and present in serum of a patient with acute lymphoblastic leukaemia. Blood 1979; 54:412-20.

${ }^{8}$ Kemp AS, Roberts Thompson SH, Neoh SH, Brown S. Inhibition of neutrophil migration by sera from patients with rheumatoid arthritis. Clin Exp Immunol 1979; 36:423-9.

'Segal AW, Coad SB. Kinetics of oxygen consumption by phagocytosing human neutrophils. Biochem Biophys Res Commun 1978; 84:611-7.
${ }^{10}$ Bentley-Phillips $\mathrm{CB}$, Black A, Greaves MW. Induced tolerance in cold urticaria caused by coldevoked histamine release. Lancet 1976; 2:63-6.

${ }^{11}$ Keller HU, Wissler JH, Hess MW, Cottier H. Distinct chemokinetic and chemotactic responses in neutrophil granulocytes. Eur J Immunol 1978; 1: $1-7$.

${ }^{12}$ Rhodes JM, Jewell DP. Serum inhibitors of leucocyte chemotaxis in Crohn's disease and ulcerative colitis. Gut 1979; 20:A911.

${ }^{13}$ Maderazo EC, Ward PA, Quintiliani R. Defective regulation of chemotaxis in cirrhosis. $J$ Lab Clin Med 1976; 85:621-30.

${ }^{14}$ Ward PA, Berenberg JL. Defective regulation of inflammatory mediators in Hodgkin's disease. $N$ Engl J Med 1974; 290:76-80.

${ }_{15}$ Ward M. Phagocytic function in Crohn's disease. Z Gastroenterol [verh] 1979; Suppl 17:116-24. 